\title{
Differentiation of haptic exploration in two age groups
}

LEONARD CIRILLO, YESHIVA UNIVERSITY

SEYMOUR WAPNER, CLARK UNIVERSITY, GEORGE RAND, TEACHERS COLLEGE, COLUMBIA UNIVERSITY

Eight adults and eight children (8-10 years) were tested in a haptic matching-to-sample procedure in which the criterial attribute was size in half of the trials and angle in the other half. Before testing on each half, the criterial attribute was verbally designated by the experimenter. Adults' exploration was different depending on the criterial attribute; the children showed no such differentiation of exploratory behavior as a result of verbal direction.

A number of investigators have suggested that verbal instructions pertinent to attributes of stimulus objects may exert selective control over the type and frequency of exploratory behaviors performed on these objects (Ellis, Bessemer, Devine, \& Trafton, 1962; Ellis, Feuge, Long, \& Pegram, 1964; Luria, 1961). The present study pursues this problem by verbally instructing the $S$ to focus on one of two attributes, according to which is criterial, in a tactual-kinesthetic matching-to-sample situation. The purposes of the study were: (a) to determine whether and how exploratory behavior differed for the two, verbally designated, criterial attributes, and (b) to determine whether there are age differences in such differentiation of exploratory behavior (Werner, 1948). Method

The stimulus materials were angles made of 2.5 $\mathrm{mm}$ wide strips of pine wood. The wood was $4 \mathrm{~mm}$ thick so that the angles projected $4 \mathrm{~mm}$ up from a cardboard surface to which they were glued. The stimuli varied in degree of angle and size of legs. There were two sets of stimuli: (a) size of legs constant (42 mm, $63 \mathrm{~mm}$ ) with angles varying $(60,90$, 120 , or $\left.150^{\circ}\right)$; (b) angles constant $\left(120^{\circ}\right)$ with size of legs varying (14/21 mm; $21 / 28 \mathrm{~mm}$; $28 / 42 \mathrm{~mm}$; $42 / 63 \mathrm{~mm})$. Within each of the two sets, two arrays were constructed by mounting the four stimuli in each array on two $21.6 \mathrm{~cm}$ square cardboards. The four stimuli were placed in different random positions on each of the two cards, with the restriction that the orientations of the stimuli were the same. Duplicates of these four stimuli were mounted separately, but in the same orientation, in the center of $21.6 \mathrm{~cm}$ square cardboards.

$S$ was seated at a table with a screen preventing him from seeing the stimuli which were placed in fixed position on the table top. The separately mounted sample stimulus was placed on S's left; the array of four stimuli, including one duplicate of the sample, was placed on S's right. All the vertices of stimuli always pointed toward S. S's task was to explore the sample and the array with his index finger only and indicate when he had found the stimulus in the array that matched the sample.

Each $S$ had 16 trials, a sequence of eight trials with each of the two sets of stimult, the order of which was counterbalanced. The eight trials for each set consisted of a given sequence of the four sample stimuli repeated once. The arrays were alternated from trial to trial. The sequence of the four sample stimuli was varied systematically in a latin square.

Before the eight trials of the set in which degree of angle was varied, $S$ was told to pick from the array that item which had the same angle as the sample stimulus; before the eight trials of the set in which the size of the legs was varied, S was told to pick that item which was the same size as the sample stimulus.

A complete audio and visual record of S's behavior was made by use of an Ampex 7500 Video Recorder. This made it possible to reexamine S's exploratory behavior to insure accurate description and measurement.

Sixteen Ss, four males and four females in each of two age groups-college students and 8-10 year old children-were employed.

\section{Results}

Number of correct matches (accuracy) and time until a match was reported (speed) were the measures in two separate analyses of variance. Each involved four factors-age (child vs adult), order (size first vs angle first), criterial property (size vs angle), blocks of trials (first four vs second four) -with repeated measures on the last two factors.

The mean number of correct matches per block of four trials was significantly $(F=9.98, \mathrm{df}=1 / 12$, $p<.01$ ) greater in the adults (mean $=2.9$ ) than in the children (mean $=2.2$ ); further, mean number of correct matches was significantly $(F=11.79, \mathrm{df}=1 / 12$, $\mathrm{p}<.001)$ greater when angle was the first criterial property (mean $=3.0$ ) than when size was the first criterial property $($ mean $\mathbf{= 2 . 2}$ ).

The mean number of seconds until a match was reported was significantly $(F=11.99, \mathrm{df}=1 / 12, \mathrm{p}<.01$ ) longer during the first block of four trials (141.6 sec) than during the second $(108.8 \mathrm{sec})$. There was a significant interaction of Order by Criterial Property $(F=4.93, \mathrm{df}=1 / 12, \mathrm{p}<.05)$ : The decrease in mean time from the first eight trials to the second eight was greater when the angle was criterial first (147.8 sec to $111.4 \mathrm{sec}$ ) than when size was criterial first $(132.3 \mathrm{sec}$ to $109.3 \mathrm{sec})$. 
Careful observation of the video recording by two judges over a number of viewings revealed eight types of exploratory finger movement that, although not mutually exclusive, could be clearly distinguished and judged accurately: (1) feeling the point of angle; (2) inserting finger into angle; (3) rotating finger in angle; (4) moving finger over or in angle; (5) keeping ball of moving finger in constant contact with inside surfaces of angle; (6) moving finger over angle and short leg only; (7) moving finger over angle and long leg only; and (8) moving finger along entire stimulus from end to end.

The frequency of each of these exploratory behaviors was obtained for each $S$ on each of four blocks of trials: the first four and the second four trials on the series with angle criterial and on the series with size criterial. These frequencies were used to rank separately the eight adults and eight children on each block of trials for each type of exploration. A Friedman two-way analysis of variance was performed for each type of exploration, separately for each of the two age groups, to determine whether the blocks of trials differed in ranked frequency of occurrence for the particular type of exploration.

For the children there were no differences between blocks of trials for any of the eight types of exploration. In contrast, for the adults these differences between blocks were significant (by $\chi^{2}$ test, $\mathrm{df}=3$ ) for the following six out of the eight types of exploration: (1) feeling the point of angle $\left(x^{2}=14.44, p<.01\right)$; (2) inserting finger into angle $\left(x^{2}=8.36, p<.05\right)$; (3) moving finger over or in angle $\left(x^{2}=13.76, p<.01\right)$; (4) keeping ball of moving finger in constant contact with inside surfaces of angle $\left(\chi^{2}=9.38, p<.01\right)$; (5) moving finger over angle and short leg only $\left(\chi^{2}=8.36\right.$, $p<.05)$; and (6) moving finger along entire stimulus from end to end $\left(x^{2}=14.96, p<.01\right)$. For the last type of exploration the mean ranks indicate that the frequency was greater on each of the two blocks of trials for which size was criterial than on either block for which angle was criterial. For all other type of exploration the frequency was greater on each block of trials for which angle was criterial than on either block for which size was criterial.

\section{Discussion}

In adults, verbal instruction leads to haptic exploration which differs in form depending on which stimulus attribute is criterial. The adult Ss explored the entire extent of the object more frequently when size was criterial than when angle was. Certain other types of exploration, tailored to obtain information as to degree of angle, were more frequent when angle was criterial. Children gave no evidence of such differentiation of exploratory behavior.

What is necessary for such differentiation of exploratory behavior to occur? Clearly, capacity to execute finely individuated movements is necessary. Further, the verbal designations of the criterial at- tributes must be understood. More important, the $S$ must be capable of treating a single perceptual object as the intersection of a number of conceptual dimensions-in this case, size and angle. Finally, he must be capable of evaluating incoming information in terms of its relevance to such a conceptual analysis in order to shape his movements to focus on conceptually pertinent information.

The failure of the children to exhibit differentiated exploratory behavior cannot be ascribed to the first two requirements since: (a) the children did in fact execute all of the types of exploratory movement and yet did not employ them differentially, and (b) great care was taken to insure that the children (810 years old) understood the verbal designations of the criterial attributes. The differences between adult and child, then, most likely depend on the development of the capacity to perform a conceptual analysis and to subordinate exploratory movements to this analysis.

The results of the present study are pertinent to those treatments of perceptual development that emphasize the role of observing or orienting responses (House \& Zeaman, 1963; Zaporozhets, 1965). The foregoing brief theoretical considerations, however, assume that the organization of exploratory activity must be considered a reflection of the development of covert, cognitive operations (Elkind \& Weiss, 1967; Piaget \& Inhelder, 1956; Revesz, 1955; Vereecken, 1961).

\section{References}

ELKIND, D., \& WEISS J. Studies in perceptual development, III: Perceptual exploration. Child Develpm., 1967, 38, 553-561.

ELLIS, H. C., BESSEMER, D. W. DEVINE, J. V., \& TRAFTON, C. L. Recognition of random tactual shapes following predifferentiation training. Percept. mot. Skills, 1962, 14, 99-102.

ELliS, H. C., FEUGE, R. L., LONG, D. D., \& PEGRAM, V. G. Evidence for acquired equivalence of cues in a perceptual task. Percept. mot. Skills, 1964, 19, 159-162.

HOUSE, B. J., \& ZEAMAN, D. Miniature experiments in the discrimination learning of retardates. In L. P. Lipsitt, \& C. C. Spiker (Eds.) Advances in child development and behavior. Vol. 1, New York: Academic Press, 1963. Pp. 313-374.

LURIA, A. R. The role of speech in the regulation of normal and abnormal behavior. New York: Liveright, 1961.

PIAGET, J., \& INHELDER, B. The child's conception of space. New York: Humanities Press, 1956.

REVESZ, G. Psychology and art of the blind. New York: Longmans, Green, 1950.

VEREECKEN, P. Spatial development. Groningen, Netherlands: J. B. Wolters, 1961.

WERNER, H. Comparative psychology of mental development. Chicago: Follet, 1948 .

ZAPOROZHETS, A. V. The development of perception in the preschool child. In P. H. Mussen (Ed.), European research in cognitive development. Monogr. Soc. Res. Child Develpm, 1965, 30, No. 2, 82-101.

Note

1. This investigation was supported by Public Health Service Grant MH 00348 from the National Institute of Mental Health. Appreciation is expressed to $L$. Mindus and $E$. Reif for creative assistance in carrying out this project. The study was completed while L. Cirillo and G. Rand were Research Associates in the Heinz Werner Institute of Developnental Psychology, Clark University. 